Publisher: GSA

Journal: GEOL: Geology

DOI:10.1130/G38382.1

\title{
1 Criticality in the planform behavior of the Ganges River
}

2 meanders

3 P.A. Carling1, N. Gupta ${ }^{2}$, P.M. Atkinson ${ }^{1,3}$, and Huang Qing $\mathrm{He}^{4}$

$4 \quad{ }^{1}$ Geography and Environment Department, University of Southampton, Southampton

$5 \quad S O 171 B J, U K$

$6 \quad{ }^{2}$ Tea Research Association, Jorhat 785008, India

$7 \quad{ }^{3}$ Faculty of Science and Technology, Lancaster University, Lancaster LA1 4YW, UK

$8 \quad{ }^{4}$ Chinese Academy of Sciences, 100864 Beijing, China

9 ABSTRACT

10 The critical point of planform transition from straight to meandering in the

11 wandering Ganges River is identifiable. Recent remote-sensing data indicate that four

12 similar meanders cut off, or attempted to cut off, after $\sim 31-35 \mathrm{yr}$, primarily due to

13 channel aggradation. As main channels aggrade, sinuosity is maximized for broad

14 channel widths and small radii of curvature and relaxes for bends of greater radii.

15 Maximized form resistance occurs close to self-organized criticality and promotes

16 cutoffs. Avulsions lead to main channel narrowing and prevent further bend

17 tightening, relaxing the system by reducing sinuosity. Thus, the wandering river

18 oscillates in space and time across the transition from a more ordered to a more

19 chaotic state. Planform behavior is described by the Jerolmack-Mohrig mobility

20 number and the Parker stability criterion, which well define meander behavior as they

21 approach criticality and then relax via partial or completed avulsions. The results have

22 significance for river engineering and river network and stratigraphic modeling. Such

23 an approach could be of practical value when predicting the behaviors of other major

24 wandering rivers. 
Publisher: GSA

\section{INTRODUCTION}

Stølum (1996) showed that channel sinuosity oscillates across a predictable critical state mediated by local cutoff (avulsion) processes. Such an adjustment is a form of self-organized criticality (SOC; Bak, 1996); when the critical state is reached, meanders adjust to regain order before evolving further. Using the criticality concept, we show that the course of the wandering Ganges River, India (study area: $24.459317^{\circ} \mathrm{N}, 88.103924^{\circ} \mathrm{E}$; Fig. 1), oscillates in space and time from a more ordered to a more chaotic state (Stølum, 1996), without change in the magnitude and frequency of external forcing. However, the SOC environment and time scale can be subject to local fixed controls (here bedrock pinch points) that condition SOC behavior (Camazine et al., 2001). The low-sinuosity river (ordered state) increases its sinuosity (chaotic state) until local bank instabilities, manifest as avulsions, lead to channel shortening to reach a low sinuosity value again. Meander regrowth follows. Thus, the critical state is defined as the planform pattern transition point. Between Farakka Barrage (West Bengal, India) and Hardinge Bridge (Sara, Bangladesh), three meanders occur, with a further meander immediately upstream of the barrage (Fig. 1[[The figure does not identify the barrage or bridge - label these in the figure? At any river kilometer, there is a low-gradient sandy main meandering channel or up to three additional lesser cutoff channels. Such rivers are termed "wandering" (Church, 1983). Floodplains and bars have no significant vegetation control. Today, the basal control point of the upstream bend is the Farakka Barrage, and at each of the other bends, translation is limited by geological pinch points (Hossain et al., 2013) that impose important control on meander evolution. Eleven maps (A.D. 1780-1967) reveal a persistent pattern of four meanders increasing in amplitude without downstream translation until cutoffs occur over 


\section{Publisher: GSA \\ Journal: GEOL: Geology \\ DOI:10.1130/G38382.1}

50 decadal time scales that lead to periodic reduction in main channel length and

51 sinuosity. In addition, 38 yr of remote sensing data (Landsat Multispectral Scanner,

52 Thematic Mapper, Indian Remote Sensing Satellites Linear Imaging Self-Scanning

53 [LISS] I and LISS III) (from 1972) were used to explore channel planform changes by

54 identifying completed avulsions or partial avulsions (Fig. 1). Main channel widths and

55 radii of curvature at meander apices were quantified for each of the four meanders

56 through time.

57 SETTING

58 The annual peak flow on the Ganges River usually occurs within a $1.5 \mathrm{~m}$ stage

59 range. Bankfull discharge is exceeded yearly, then the low natural levees are

60 overtopped by shallow floodplain flow or are breached by small cutoffs that transect

61 the major meander loops. These cutoffs scour the floodplains (Coleman, 1969), but

62 the main channel does not realign. Rather, it takes several years for the main flow to

63 adopt any enlarging cutoff channel (Fig. 1). Upstream of the Farakka Barrage the

64 sediment load is $729 \times 10^{6} \mathrm{t} \mathrm{yr}^{-1}$ (Wasson, 2003) which, due to the barrage, reduces

65 downstream to $300-500 \times 10^{6} \mathrm{t} \mathrm{yr}^{-1}$ at Hardinge Bridge (Hossain et al., 2013). The

66 barrage (constructed in 1975) was fully aggraded by 1995 (Fig. 2), and much

67 sediment now passes by canal to the Bhagirathi-Hooghly River. Thus, the sediment

68 load downstream of the barrage reduces by $\sim 41 \%-68 \%$.

69 Four similar meander bends were studied (Fig. 1): one upstream (R1) and

70 three downstream (R2-R4) of the barrage. All bends developed simultaneously and

71 cut off, or attempted to cut off, by chute development over similar time scales (31-35

72 yr). Thus, although the remote sensing time series is too short to develop a statistical

73 assessment of cutoff frequency, there are four replicates of the cutoff phenomenon.

74 CONDITIONS FOR AVULSION 


\section{Publisher: GSA \\ Journal: GEOL: Geology \\ DOI:10.1130/G38382.1}

The avulsion condition largely is due to channel aggradation (Jerolmack and

Mohrig, 2007) that forces overbank flows to occur more frequently. However, tightening bends deepen on their outer banks (Seminara, 2006), and increasing bend flow resistance causes both elevation in the outer bank flow level and increased bank erosion, which increases [[Corre $\Omega$ ] channel width (Germanoski and Schumm, 1993). These conditions jointly are conducive to avulsion. Thus, the critical cutoff condition can be determined for each bend and depends on (1) channel geometry, (2) discharge, and (3) aggradation rate.

\section{Channel Geometry}

The radius of curvature $(r)$ was determined for each of the main channel bends. The radii of curvature decreased through time, whereas the channel widths $(B)$ often increased (Hossain et al., 2013). The inability of point bar progradation to match the rate of bend apex recession, such that $B$ increases as bends tighten, has been noted elsewhere (Kasvi et al., 2015). The condition preceding a completed (or attempted) cutoff and a sudden decrease in sinuosity $(S)$ occurred when the bend radius fell to between $5000 \mathrm{~m}$ and $2000 \mathrm{~m}$. Thus, cutoff likelihood, in part, can be defined by the ratio $r / B$ (Howard and Knutson, 1984). To cut off, the river must flow overbank and avulse by rapid erosion of the levee and floodplain surface. The minimum condition for overbank flow is bankfull discharge (van Dijk et al., 2014) plus super-elevated outer bank flow. For bankfull flow $\left(Q_{b} \sim 56,633 \mathrm{~m}^{3} \mathrm{~s}^{-1}\right.$; Coleman, 1969), for the channel width ( $4000 \mathrm{~m})$ immediately before cutoff occurs, and for the minimum radius of curvature $(2000 \mathrm{~m})$, the water surface super-elevation $(\Delta y)$ is:

$$
\Delta y=\frac{c \bar{U}^{2} \bar{B}}{r g}
$$

where $c$ is a coefficient (0.5) for subcritical flows, the bankfull bulk-flow velocity $\bar{U}=Q_{\mathrm{b}} / \bar{h} \bar{B}$, where $\bar{B}$ and $\bar{h}$ are average values of the channel width and depth $(h)$ 
Publisher: GSA

Journal: GEOL: Geology

DOI:10.1130/G38382.1

100 at bankfull, and $g$ is acceleration due to gravity. Bankfull velocity is low (on the order

101 of $1 \mathrm{~m} \mathrm{~s}^{-1}$ ) such that inertia is small. Thus, super-elevation at the bankline is no more

102 than $\sim 50 \mathrm{~mm}$ above the channel center water surface. So, for these shallow overbank

103 conditions, near-bankfull flows alone are not likely to induce cutoff (Howard, 2009).

104 Rather, sustained outer-bank erosion, causing $r / B$ to continue to decrease and further

105 channel aggradation, is required to elevate water levels additionally. Alternatively,

106 discharges much above bankfull are required.

\section{Discharge}

108 Rapid erosion of the outside bend will occur if discharge is adequate to entrain

109 bank material for a sufficient time (Edmonds et al., 2009). Bendway flow resistance

110 will reach a maximum as the radius of curvature reaches a minimum value. The

111 straight channel shear stress $\left(\tau_{\mathrm{T}}\right)$ due to skin friction $(f)$ is:

$112 \tau_{\mathrm{T}}=\rho g R S_{\mathrm{e}}=\rho f \bar{U}^{2}$,

113 where $\rho$ is the density of water, $R$ is the hydraulic radius, and $S_{\mathrm{e}}$ is the energy slope.

114 The hydraulic radius is $\sim 16 \mathrm{~m}$ with a regional bankfull $S_{\mathrm{e}}$ of $5-6 \times 10^{-5}$ (Coleman,

115 1969). These data provide an estimate of unit shear stress on the order of $10 \mathrm{~N} \mathrm{~m}^{-2}$.

116 Determining additional form resistance induced by bends is complex (e.g., Chang,

117 1983). However, for illustrative purposes, we utilize the method of Leopold et al.

118 (1960) to estimate bend form shear stress $\left(\tau_{\mathrm{B}}=\rho g \bar{h} S_{\zeta}\right)$ using an energy dissipation

$119 \operatorname{term}\left(\bar{h} S_{\zeta}\right)$ :

120

$$
\bar{h} S_{\zeta}=\frac{\bar{U}^{2}}{g}\left(\frac{B}{r}-0.5\right)-h\left(1+1.5 F^{0.66}\right)
$$

121 where $F$ is the near-bank Froude number for given local depth $h$. For the minimum

122 values of $r / B$, the form-induced shear stress can be up to an order of magnitude larger

123 than the skin shear stress. For greater $r / B$ values, the form resistance declines. When 
Publisher: GSA

Journal: GEOL: Geology

DOI:10.1130/G38382.1

124 avulsions were imminent, values of $r / B$ are consistent for all four reaches $(\overline{1.29}$,

125 standard deviation $0.72 ; \mathrm{n}=27)$ but smaller than those values $(\sim 3)$ reported by Begin

126 (1986) and Howard and Knutson (1984) for the condition when bank retreat through

127 erosion is maximized. Thus, the ability of the channel to develop significant form

128 resistance and adjust through increasing sinuosity is maximized for small radii of

129 curvature and decreases for bends of greater amplitude. However, increasing form

130 resistance as bends tighten induces a backwater effect and super-elevation that is

131 conducive to cutoff before $r / B$ is maximized, preventing further bend tightening and

132 relaxing the system by reducing sinuosity.

133 Aggradation

134 The aggradation rates for meander bends R2-R4 are unknown, but for R1,

135 channel aggradation and subsequent attempted avulsion were induced by backwater

136 sedimentation above the barrage. A linear and then asymptotic approach to constant

137 zero aggradation is typical of impoundments (Wu et al., 2012) and provides a

138 maximum aggradation rate, $\sim 0.18 \mathrm{~m} \mathrm{yr}^{-1}$, to use as a scalar in $\mathrm{R} 1$ (Fig. 2A). Bend

139 extension increases rapidly once one-third of the impoundment depth is filled (Fig.

140 2B). For R2-R4, the aggradation rate $\left(V_{\mathrm{a}}\right)$ is assumed to be proportional to the

141 reduction in the sediment load $\left(V_{\mathrm{a}}=300 / 729 \times 0.18 \mathrm{~m} \mathrm{yr}^{-1}\right)$ below the Farakka

142 Barrage. As the system aggraded, channel sinuosity increased, and attempted

143 avulsions and cutoffs developed (Figs. 2 and 3). As, channel aggradation rate,

$144 T_{\mathrm{A}}\left[\left[\right.\right.$ Clarify how this differs fre $\left.\left.V_{\mathrm{a}}\right]\right]$, mediates the rate of lateraleresion, $T_{\mathrm{C}}$, the

145 latter a key variable to define critical state (Stølum, 1998), consideration of $T_{\mathrm{A}}: T_{\mathrm{C}}$ can

146 define the critical state of the planform pattern transition if other factors are

147 significantly subordinate.

148 PLANFORM SCALING MODEL 


\section{Publisher: GSA \\ Journal: GEOL: Geology \\ DOI:10.1130/G38382.1}

150 (2007) approach to calculate the avulsion frequency $\left(f_{\mathrm{A}}\right)$ of a river. The avulsion

151 frequency,

$$
f_{\mathrm{A}}=\frac{V_{\mathrm{a}} N}{\bar{h}},
$$

153 is known approximately. Each reach avulsed, or tried to avulse, at a time scale of

$154 \sim 31-35 \mathrm{yr}$, so $f_{\mathrm{A}}$ can be set to 0.03 for active channels $N=1-4$, with an average

155 channel depth of $\bar{h}=22 \mathrm{~m}$. Jerolmack and Mohrig (2007) developed a channel

156 mobility number $(M)$ to discriminate single-channel versus multichannel form:

$$
M=\frac{T_{\mathrm{A}}}{T_{\mathrm{C}}}=\frac{\bar{h}}{B} \frac{V_{\mathrm{c}}}{V_{\mathrm{a}}}
$$

where $T_{C}$ is the time to migrate one channel th and $V_{\mathrm{c}}$ is the bank erosion rate. $M=$

$159 T_{\mathrm{A}} / T_{\mathrm{C}}=1$ defines the critical planform pattern transition (Jerolmack and Mohrig,

160 2007). The general trend of $M$ in Figure 3 shows the temporal trajectories of reach

161 behavior. For $M>>1$, a single, laterally mobile sinuous channel is expected. For $M \approx$

1621 , then transition is expected between a single channel and multiple channels. For $M$

$163<<1$, a multichannel avulsive system is expected. In accord with SOC, few, small

164 avulsions release energy which suppresses the likelihood of large avulsions, whereas

165 large avulsions increase the energy capacity of the network, which is a destabilization

166 (Stølum, 1998). Accordingly, the network is attracted to $M \approx 1$. Such a simple model

167 uses few parameters to elucidate emergent behavior without appeal to detailed

168 process.

$169 M$ is used here with the Parker (1976) channel stability criterion ( $(\varepsilon)$,

$170 \quad \varepsilon=S_{\mathrm{e}} \sqrt{g \bar{h} \bar{B}^{4}} / Q$

171 to define system trend through channel pattern phase space (Fig. 4), where $Q$ is a

172 formative discharge (bankfull value). A single-thread channel should dominate when 


\section{Publisher: GSA \\ Journal: GEOL: Geology \\ DOI:10.1130/G38382.1}

$173 \varepsilon<<1$, while a braided form should be common for $\varepsilon \geq 1$. Jerolmack and Mohrig

174 (2007) argued that a plot of $M$ versus $\varepsilon$ discriminated between planforms representing

175 rivers at a single point in time across spatial scales. In contrast, we use the $M-\varepsilon$ phase

176 space to explore meander bend evolutions through time as the channel morphology

177 varies across the point of criticality due to hydraulic and morphological forcing. It is

178 evident that meander R1 differs in its behavior in contrast to R2-R4, in that the Parker

179 criterion for R1 lies between values of 0.6 and 1.5 while the other meanders exhibit

180 values typically $<0.4$. The values of $M=1$ and $\varepsilon<0.4$ define four quadrant phase

181 spaces for channel planform discrimination (Fig. 4).

\section{DISCUSSION}

183 A power-law avulsion distribution may characterize SOC behavior but, as

184 with many studies (Hooke, 2007), our reach length is inadequate for this test. In

185 addition, a time constant is imposed on the Ganges' SOC cutoff behavior by spatial

186 pinch points, such that cycling occurs, similar to other guided SOC phenomena

187 (Prokopenko et al., 2014).

188 So, we focused on the critical state: defining avulsion as an autogenic response

189 of a channel when it cannot adjust further through gradual variation of sinuosity

190 (Stølum, 1996). As $M$ approaches 1, there is an increased propensity for channel

191 alignment to reset by cutoff to regain low sinuosity.

192 In a flume, lacking bank-stabilizing vegetation, cutoffs occurred at a small

193 value of $S \approx 1.2$, preventing the development of more sinuous channels (Braudrick et

194 al., 2009). The Ganges River also is vegetation free and tends to avulse when $S$ is $\sim 1.3$

195 (Fig. 3). However, the situation is not simple, as a new avulsion relaxes the system

196 such that both cutoff and main channel can be simultaneously active. There is not

197 usually a simple abandonment of the main channel in favor of the new channel (Fig. 
Publisher: GSA

Journal: GEOL: Geology

DOI:10.1130/G38382.1

198 1). These "soft avulsions" (Edmonds et al., 2011) divert some discharge and sediment

199 from the main channel (Coleman, 1969), but much load continues down the main

200 channel. The effects of cutoffs on main channel response are poorly known

201 (Seminara, 2006). However, as main channel discharge declines, deposition occurs in

202 the main channel below the avulsion point, reducing channel width (Sorrells and

203 Royall, 2014); the main thalweg depth is less affected as long as the main channel

204 discharge remains greater than the cutoff discharge. The relaxation in the system, due

205 to the soft avulsion, results in the main meander $r / B$ increasing as $B$ adjusts more

206 readily than $r$, which sustains potential for bank erosion downstream of the avulsion

207 as flow is increasingly confined by channel narrowing through time (Coleman, 1969).

208 Thus, soft avulsion may assist a channel in maintaining its meandering habit and so

209 delay a catastrophic reduction in sinuosity. Notwithstanding the relaxation due to $B, r$

210 also increased in three of the meanders, preventing or delaying avulsion (Fig. 3).

211 Meander R1, influenced by Farakka Barrage backwater, cycles from

212 anastomosed-braided to a single-channel braided pattern (Fig. 4). This pattern differs

213 from those of R2-R4, which cycle from avulsive-anastomosed to a sinuous single-

214 channel pattern, as is typical of wandering rivers. Thus, the imposition of the barrage,

215 with consequent accelerated upstream aggradation and reductions in slope and

216 channel depth, but broadening of the channel, caused a shift from a wandering to a

217 braided pattern, as indexed by the values of $\varepsilon$. Thus, our analysis indicates that rapid

218 aggradation in a wandering river (R1) leads to braiding (viz. Carson, 1984, his

219 wandering type II). Moreover, the wandering planform is sustainable through time,

220 with three meanders (R2-R4) adjusting similarly through time from meandering to a

221 straighter main channel planform by the development of bend cutoffs. So, the

222 wandering habit is not necessarily indicative of a channel in short-term transition 
Publisher: GSA

Journal: GEOL: Geology

DOI:10.1130/G38382.1

223 between single-channel meandering and braiding (Carson, 1984). To date, the

224 reduction in sediment load downstream of the barrage has not changed the channel

225 pattern, but a more stable meandering habit is predicted by Equation 5 (viz. Carson,

226 1984, his wandering type I) and has been observed recently (Hossain et al., 2013).

227 Consequently, a considerable time lag can be associated with any transition. The

228 similar trend in behavior among all four meanders through similar time scales is

229 highly significant in that criticality develops naturally in the meandering system.

230 Clearly, the meanders are affected by the barrage. Nevertheless, the boundary

231 conditions of a critical bend radius relative to channel apex width, the imposed

232 discharge, and the aggradation rate drive the development of cutoffs as indexed by $M$,

233 which reduces toward unity as the likelihood of cutoff becomes pronounced. This

234 behavior develops independently of the presence of negligible bank-side vegetation.

235 Thus, although vegetation can constrain planform, its presence is not a prerequisite to

236 enable the wandering river planform to persist. By corollary, the behavior of other

237 wandering rivers could be assessed in terms of cutoff criticality. Although channel

238 behavior is explained by SOC, limitations remain; the detailed cutoff processes and

239 how changes are transmitted beyond the cutoff locale require identification.

240 CONCLUSIONS

241 Low-sinuosity meanders on the Ganges River behaved similarly to each other

242 over $\sim 35 \mathrm{yr}$ without downstream translation as sinuosity increased. Two

243 meanders avulsed toward the end of the period, a third developed a soft avulsion, and

244 the fourth was close to avulsion.

245 The critical bend radius-to-width ratio of $\overline{1.29}$ was associated with avulsion.

246 The role of super-elevation was accounted for in the avulsion process, but was small. 
Publisher: GSA

Journal: GEOL: Geology

DOI:10.1130/G38382.1

247 Rather, as shown for a barrage-effected meander, sinuosity increased once the

248 backwater developed fully and aggradation drove the avulsion process.

249 Self-organized criticality, with a mobility number $(M)$ tracking meander

250 development, showed that the critical transition is defined by $M \approx 1$ when avulsion

251 was imminent (Fig. 4). Channel phase space (Fig. 4) defined by Parker's braiding

252 criterion and $M$ demonstrates that the meander upstream of the barrage adjusted from

253 an anastomosed braided system to a single-thread braided channel. Downstream, the

254 system follows a wandering river trajectory varying through time from a meandering

255 to an avulsive-anastomosed planform and then returns to meandering after $\sim 35 \mathrm{yr}$.

256 ACKNOWLEDGMENTS (?)

257 [[Would you like to acknowledge paper's reviewers (by name) in an

258 Acknowledgments section?]l]

259 REFERENCES CITED

260 Bak, P., 1996, How Nature Works: The Science of Self-Organized Criticality: New

261 York, Springer-Verlag, 212 p., doi:10.1007/978-1-4757-5426-1.

262 Begin, Z.B., 1986, Curvature ratio and rate of river bend migration-Update: Journal

263 of Hydraulic Engineering, v. 112, p. 904-908, doi:10.1061/(ASCE)0733-

$2649429(1986) 112: 10(904)$.

265 Braudrick, C.A., Dietrich, W.E., Leverich, G.T., and Sklar, L.S., 2009, Experimental

266 evidence for the conditions necessary to sustain meandering in coarse bedded

267 rivers: Proceedings of the National Academy of Sciences of the United States of

268 America, v. 106, p. 16,936-16,941, doi:10.1073/pnas.0909417106.

269 Camazine, S., Deneubourg, J.-L., Franks, N., Sneyd, J., Theraulaz, G., and Bonabeau,

270 E., 2001, Self-Organization in Biological Systems: Princeton, New Jersey,

271 Princeton University Press.[[Provide total number of pages]] 


\section{Publisher: GSA \\ Journal: GEOL: Geology \\ DOI:10.1130/G38382.1}

272 Carson, M.A., 1984, Observations on the meandering-braided river transition,

273 Canterbury Plains, New Zealand: Part two: New Zealand Geographer, v. 40,

$274 \quad$ p. 89-99, doi:10.1111/j.1745-7939.1984.tb01044.x.

275 Chang, H.H., 1983, Energy expenditure in curved open channels: Journal of

276 Hydraulic Engineering, v. 109, p. 1012-1022, doi:10.1061/(ASCE)0733-

277 9429(1983)109:7(1012).

278 Church, M., 1983, Pattern of instability in a wandering gravel bed channel, in

279 Collinson, J.D., and Lewin, J., eds., Modern and Ancient Fluvial Systems:

280 International Association of Sedimentologists Special Publication 6, p. 169-180,

281 doi:10.1002/9781444303773.ch13.

282 Coleman, J.M., 1969, Brahmaputra River: Channel processes and sedimentation:

283 Sedimentary Geology, v. 3, p. 129-239, doi:10.1016/0037-0738(69)90010-4.

284 Edmonds, D.A., Hoyal, D.C.J.D., Sheets, B.A., and Slingerland, R.L., 2009,

285 Predicting delta avulsions: Implications for coastal wetland restoration: Geology,

286 v. 37 , p. $759-762$, doi:10.1130/G25743A.1.

287 Edmonds, D.A., Paola, C., Hoyal, D.C.J.D., and Sheets, B.A., 2011, Quantitative

288 metrics that describe river deltas and their channel networks: Journal of

289 Geophysical Research, v. 116, F04022, doi:10.1029/2010JF001955.

290 Germanoski, D., and Schumm, S.A., 1993, Changes in braided river morphology

291 resulting from aggradation and degradation: The Journal of Geology, v. 101,

292 p. $451-466$, doi:10.1086/648239.

293 Hooke, J.M., 2007, Complexity, self-organisation and variation in behaviour in

294 meandering rivers: Geomorphology, v. 91, p. 236-258,

295 doi:10.1016/j.geomorph.2007.04.021. 
Publisher: GSA

Journal: GEOL: Geology

DOI:10.1130/G38382.1

296 Hossain, M.A., Gan, T.Y., Basar, A., and Baki, M., 2013, Assessing morphological

297 changes of the Ganges River using satellite images: Quaternary International,

298 v. 304, p. 142-155, doi:10.1016/j.quaint.2013.03.028.

299 Howard, A.D., 2009, How to make a meandering river: Proceedings of the National

300 Academy of Sciences of the United States of America, v. 106, p. 17,245-17,246,

$301 \quad$ doi:10.1073/pnas.0910005106.

302 Howard, A.D., and Knutson, T.R., 1984, Sufficient conditions for river meandering:

303 A simulation approach: Water Resources Research, v. 20, p. 1659-1667,

304 doi:10.1029/WR020i011p01659.

305 Jerolmack, D.J., and Mohrig, D., 2007, Conditions for branching in depositional

306 rivers: Geology, v. 35, p. 463-466, doi:10.1130/G23308A.1.

307 Kasvi, E., Vaaja, M., Kaartinen, H., Kukko, A., Jaakkola, A., Flener, C., Hyyppä, H.,

308 Hyyppä, J., and Alho, P., 2015, Sub-bend scale flow-sediment interaction of

309 meander bends - A combined approach of field observations, close-range remote

310 sensing and computational modelling: Geomorphology, v. 238, p. 119-134,

311 doi:10.1016/j.geomorph.2015.01.039.

312 Leopold, L.B., Bagnold, R.A., Wolman, M.G., and Brush, L.M., 1960, Flow

313 resistance in sinuous or irregular channels: U.S. Geological Survey Professional

$314 \quad$ Paper 282-D, p. 111-134.

315 Parker, G., 1976, On the cause and characteristic scales of meandering and braiding in

316 rivers: Journal of Fluid Mechanics, v. 76, p. 457-480,

317 doi:10.1017/S0022112076000748.

318 Prokopenko, M., Polani, D., and Ay, N., 2014, On the cross-disciplinary nature of

319 guided self-organization, in Prokopenko, M., ed., Guided Self-Organization:

320 Inception: New York, Springer, p. 3-15, doi:10.1007/978-3-642-53734-9_1. 
Publisher: GSA

Journal: GEOL: Geology

DOI:10.1130/G38382.1

321 Seminara, G., 2006, Meanders: Journal of Fluid Mechanics, v. 554, p. 271-297,

322

323

324

325

326

327

328

329

330

331

332

333

334

335

336

337

338

339

340

\section{1}

342

343

344 doi:10.1017/S0022112006008925.

Sorrells, R.M., and Royall, D., 2014, Channel bifurcation and adjustment on the upper Yadkin River, North Carolina (USA): Geomorphology, v. 223, p. 33-44, doi:10.1016/j.geomorph.2014.06.020.

Stølum, H.-H., 1996, River meandering as a self-organization process: Science, v. 271, p. 1710-1713, doi:10.1126/science.271.5256.1710.

Stølum, H.-H., 1998, Planform geometry and dynamics of meandering rivers: Geological Society of America Bulletin, v. 110, p. 1485-1498, doi:10.1130/00167606(1998)110<1485:PGADOM>2.3.CO;2.

van Dijk, W.M., Schuurman, F., van de Lageweg, W.I., and Kleinhans, M.G., 2014, Bifurcation instability and chute cutoff development in meandering gravel-bed rivers: Geomorphology, v. 213, p. 277-291, doi:10.1016/j.geomorph.2014.01.018.

Wasson, J., 2003, A sediment budget for the Ganga-Brahmaputra catchment: Current Science, v. 84, p. 1041-1047.

Wu, B., Zheng, S., and Thorne, C.R., 2012, A general framework for using the rate law to simulate morphological response to disturbance in the fluvial system: Progress in Physical Geography, v. 36, p. 575-597, doi:10.1177/0309133312436569.

\section{FIGURE CAPTIONS}

Figure 1. Development of Ganges River meanders R1-R4 in A.D. 1972-2011. Inset: Location map showing study area. 
Publisher: GSA

Journal: GEOL: Geology

DOI:10.1130/G38382.1

345 Figure 2. A: Derivation of maximum channel aggradation rate, Ganges River, India.

346 Triangles show years $(Y)$ of aggradation; squares are years after Farakka Barrage was

347 full. B: Sinuosity of the R1 meander over time. "Full"'[[Explain the need for

348 quotation marks (i.e., what is meant by "full”)]l channel aggradation-accelerates

349 meander sinuosity.[[In the figure, panel B, it is not clear what is meant by "Years

350 of change in Base Level" - do you mean "Year" (Dular, as in calendar year)?

351 (Also, “Change” should be capitalized for consistency)]]

352

353 Figure 3. Mobility number and sinuosity versus year for Ganges River meanders.

354 Circles are mobility number $(M)$ fitted with polynomial functions; squares are

355 sinuosity of main channel; triangles are cutoff sinuosity. Black arrows are cutoff

356 initiation dates; white arrow is date of cutoff failure (see Fig. 1).

357

358 Figure 4. Channel pattern phase space: AB — anastomosed-braided; BS—braided-

359 single; AW — wandering; S—sinuous-single. Time trends, labeled with calendar years

360 A.D., are shown for Ganges River meanders R1 and R4. 